Teknomekanik

Vol.3, No.1, May 2020, pp. $28 \sim 35$

\title{
Effect of Spring Back on Formation Process of Sheet Metal Bending Plates
}

\author{
Purwatono $^{1}$, Nelvi Erizon ${ }^{2}$, Nofri Helmi ${ }^{3}$, Muhammad Akhbar ${ }^{4}$ and Muhibuddin 5 \\ ${ }^{1}$ Departement of Mechanical, Faculty of Engineering, Universitas Negeri Padang, Padang, Indonesia \\ ${ }^{5}$ Mechanical and Industrial Engineering, Faculty of Engineering, Universitas Syiah Kuala, Indonesia
}

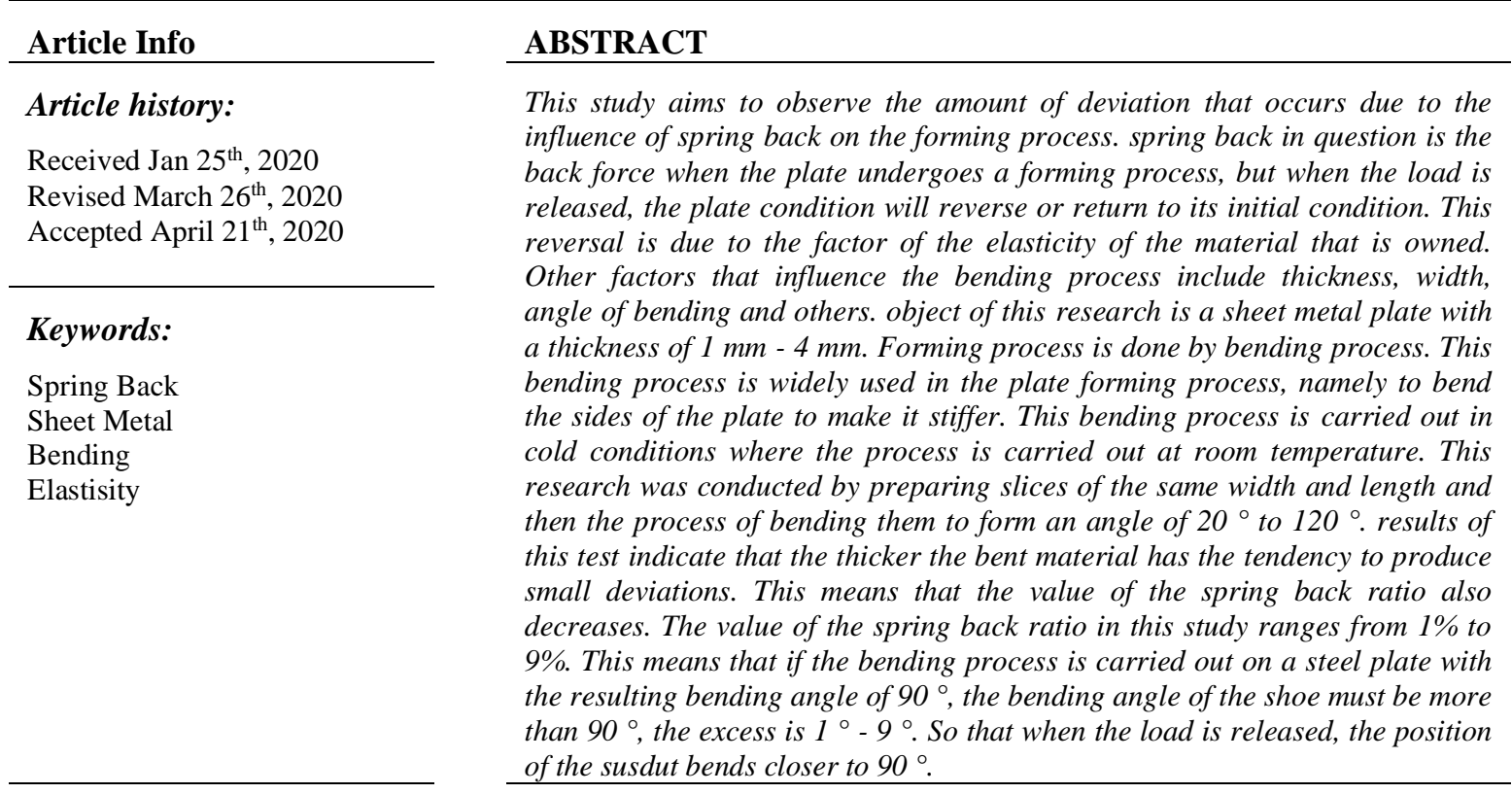

Corresponding Author:

Muhammad Akhbar,

Jurusan Teknik Mesin, Fakultas Teknik, Universitas Negeri Padang

Jln. Prof. Dr. Hamka Air Tawar, Padang (25131), Sumatera Barat, Indonesia

Email: makhbar49@gmail.com

\section{INTRODUCTION}

Spring back is a term that is often used in the plate forming process, where the spring back is the back force of the plate when the forming load is removed. Due to this reverse force, the dimensions of the plate size will change. This change must be taken into account because for the production in large numbers it is possible that formation errors can occur due to this spring back. A simple example can be seen in the bending of the plate, where the bending angle is expected to be $90^{\circ}$, the angle of formation that is formed must exceed $90^{\circ}$, so that when the plate is subjected to a reverse force the forming position is exactly $90^{\circ}$. It is this excess forming angle that will be observed to produce a proper formation. If the production is carried out in large quantities, it is expected that all production will not experience deviations, because if there is a wrong formation it will be detrimental to production both in processing time and in the subsequent process, so that production costs will increase.

This research study focuses on the observation of the cold forming process where the magnitude of the return force that occurs in each forming process can be observed by varying the plate thickness, width and volume of plate formation. The cold forming process carried out in this study is the bending process. The reason for applying this bending process is because this process is most widely used for working various components using thin plate material. Examples of the use of this thin plate material are widely seen in the car body industry, trains and engine cuppers and so on. The product that uses thin plate materials for vehicle body parts has several advantages including: the components become lighter with the process of forming a thin plate becoming stiffer and stronger resistant to vibrations, the body assembly process is simpler by using spot welding or electrical resistance welding so that operating costs workmanship becomes cheaper.

Formulation of the problem that arises in this study is how the effect of this spring returns to the thin plate ordering process that is carried out. Research objective was to determine the magnitude of the effect of 
this spring back on the plate forming process, so that it is expected that the formation results will obtain the correct dimensions in accordance with the expected size of the work image. Results of this study are expected to be used for consideration in the process of forming thin plates. So that during the forming process, the magnitude of this reverse force can be exaggerated according to the shape, thickness, width of the plate that is undergoing formation. These advantages must match the desired size shape.

\section{METHOD}

Research method applied is an experimental method by following the research procedure as follows:

1. Making specimens of formation with variations in plate width and length. The dimensions of the forming width are from $10-100 \mathrm{~mm}$

2. Preparation of forming dies and punches

3. Bending angle setting

4. Measurement of the spring back effect that occurs using a bevel protactor. The accuracy of the tool reaches 0.5 degrees.

5. Performing the forming process repeatedly by tabulating all measurement data

6. Analyze research data.

7. Graph analysis result and spring back effect measurement.

8. Make a research report

\section{RESULTS AND ANALYSIS (10 PT)}

In the metal forming operation, the highly nonlinear deformations processes tend to generate a large amount of elastic strain energy in the metal material besides of the some plastic deformation area. The elastic energy, which stored in the metal sheet during the forming, is subsequently released after the forming pressure is removed. This release of energy is the driving force for spring-back of sheet metal forming [1]. In this forming operation, the deformation is not linear or there is plastic deformation but it is still influenced by the spring back effect. According to Afri Sujarmanto (2007) that the plastic forming process with a working temperature below the recrystallization temperature [2]. Tension stress type of steel can be identified as follows:

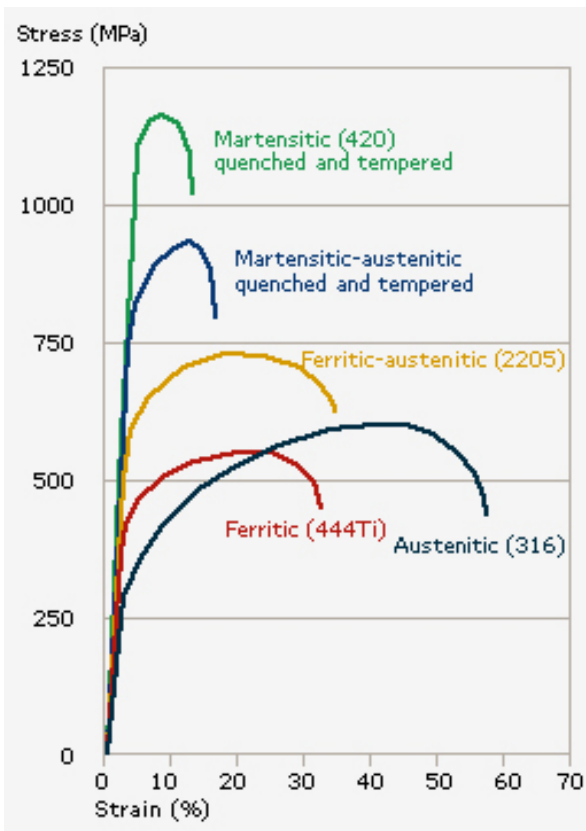

Figure 1 : Tension Stress Types of Steel

Figure 1 shows the ratio of the yield stress and strain of martensitic, ferritic, austenitic steels. Martensitic steels have a higher yield stress than ferritic or austenitic steels, but the strain is inversely proportional to the strain that occurs. ferritic and austenitic steels have nearly the same yield stress, but the austenitic steels have a greater tendency to strain. Therefore, austenitic steel is used for the basic materials of easy to form plates. When this austenitic steel is stretched, the condition will not experience cracks or deforms. 


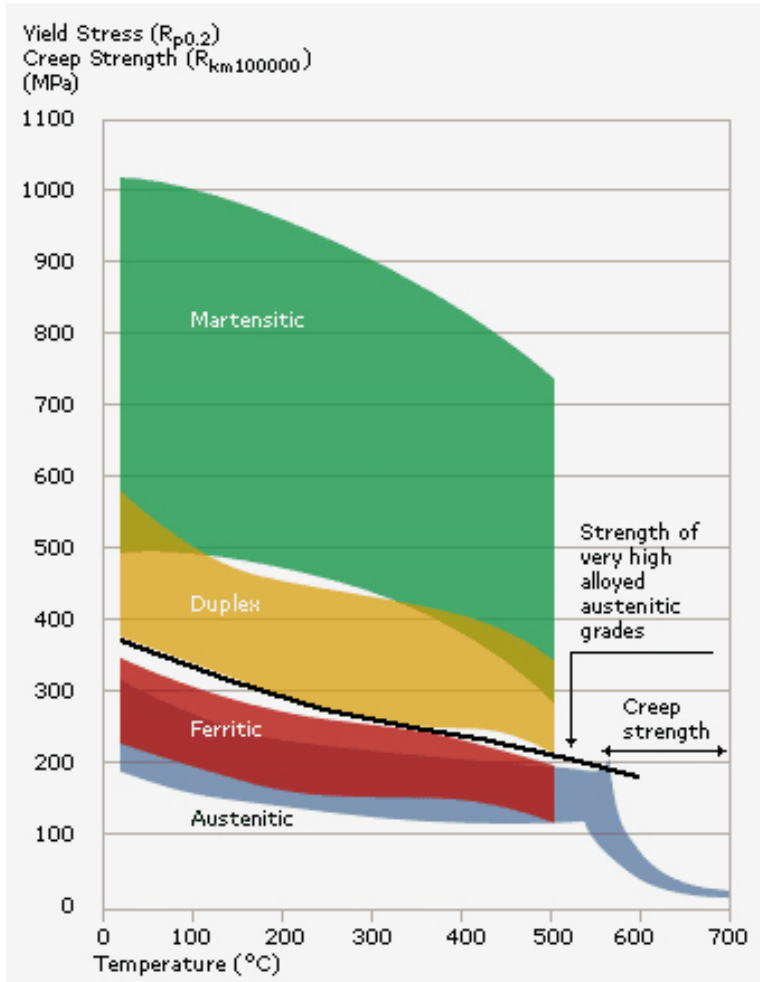

Figure 2 : Graph of Yield Stress and Temperature

\subsection{Spring Back}

Spring back is a back force caused by the influence of the elasticity of the plate material which undergoes the forming process. Amount of this reverse force is determined by the price of the elastic modulus of the material. In this bending process, the spring back must be considered. Usually due to spring back there is a deviation from the bending angle that is formed. A worker must be able to calculate the size of this spring back. A simple example can be shown during the bending process if it is desired to form a bending with an angle of 90, then the amount of compression angle on the bending shoe must be reduced from $90^{\circ}\left(<90^{\circ}\right)$. So that when the bending shoe is removed, the formation angle is equal to $90^{\circ}$. The process of spring back in the formation by bending can be seen as in Figure 3 .

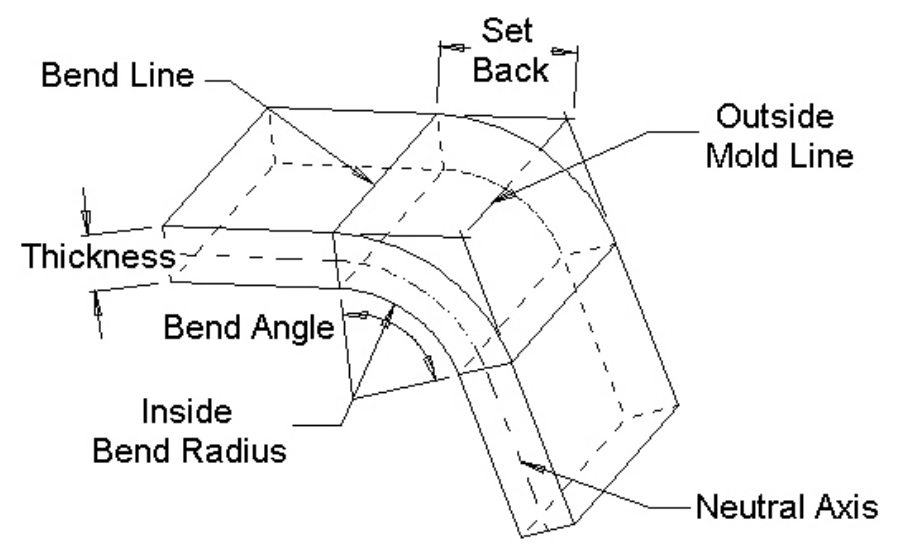

Figure 3 : Process of Spring Back on Formong by Bending 
In Figure 3 the formation process shows that the neutral axis is a line that is not influenced by the formation process. Position of the outside (outside mold line) is an area that has stretched or has increased in length. Lower part (bend radius) of the plate is shrinking / shrinking, meaning that the plate is shortening.

1. In bending, after plastic deformation there is an elastic recovery this recovery is called spring back.

2. Spring back can be calculated approximately in terms if radii Ri and $\mathrm{Rf}$

3. $\mathrm{Ri} / \mathrm{Rf}=4(\mathrm{Ri} \mathrm{Y} / \mathrm{ET}) 3-3(\mathrm{Ri} \mathrm{Y} / \mathrm{ET})+1$

4. Spring back Increases as (R/T ratio \& yield stress of material) increases as elastic modulus $\mathrm{E}$ decrease

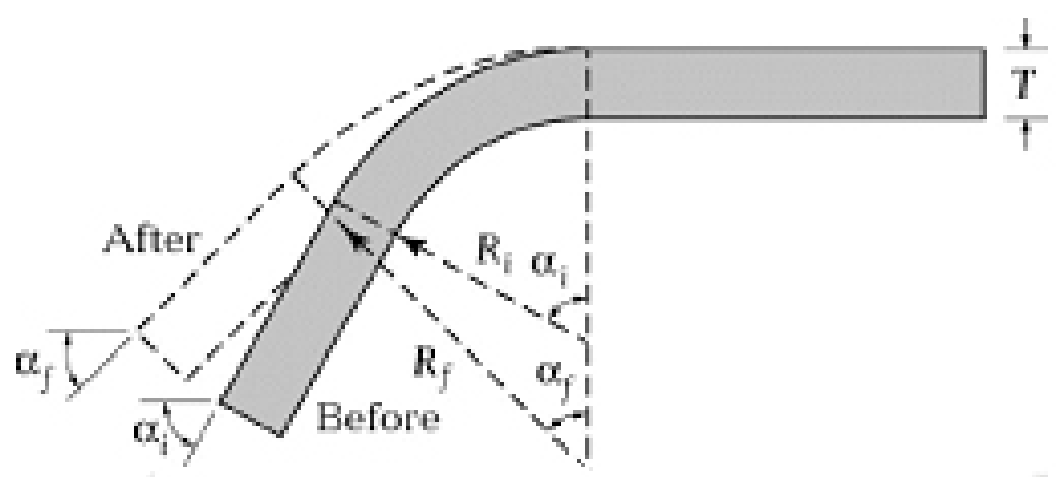

Figure 4 : Spring Back Effect (University of louisiana at Lafayette 2007)

The magnitude of the dimensional change in the forming results after the forming pressure is removed is a characteristic of metal which has its own elasticity. This change occurs as a result of the change in strain generated by elastic selection. If the load is removed the total strain is reduced due to the elastic recovery. Elastic recovery also means spring reversal, which is likely to be greater if the yield stress is higher, or the modulus of elasticity is lower and the strain of the plastic is greater. Spring back is present in all forming processes, but the bending is most easily observed. Radius of curvature before the load is removed Ro is smaller than the radius after the load is removed Rf. The bending ability is the same before and after bending, so:

$$
B=\left(R o+\frac{h}{2}\right) \alpha o=\left(R f+\frac{h}{2}\right) \alpha f
$$

Spring Return Ratio $K s=\alpha f / \alpha O$ the equation becomes:

$$
K s=\frac{\alpha f}{\alpha o}=\frac{R o+h / 2}{R f+h / 2}=\frac{2 R o / h+1}{2 R f / h+1}
$$

\subsection{Research Data Tabulation}

This research data tabulation aims to facilitate the process of further data analysis. These data will be interpreted in accordance with the objectives of research testing. The research data were grouped based on the thickness of the tested plate. 
Table 1: Zinc Plate BJLS 30 Thick $0.30 \mathrm{~mm}$

\begin{tabular}{|c|c|c|c|c|c|c|}
\hline \multirow{2}{*}{ No } & \multirow{2}{*}{ Angel $\alpha$} & \multicolumn{4}{|c|}{ Thick $0.3 \mathrm{~mm}$} & \multirow{2}{*}{$\begin{array}{c}\text { Ratio (\%) } \\
\text { Spring Back }\end{array}$} \\
\hline & & 1 & 2 & 3 & Average & \\
\hline 1 & 20 & 12 & 11 & 12 & 11,67 & 41,67 \\
\hline 2 & 40 & 25 & 25 & 26 & 25,33 & 36,67 \\
\hline 3 & 60 & 47 & 45 & 44 & 45,33 & 24,44 \\
\hline 4 & 80 & 67 & 68 & 65 & 66,67 & 16,67 \\
\hline 5 & 90 & 77 & 74 & 75 & 75,33 & 16,30 \\
\hline 6 & 100 & 84 & 86 & 85 & 85 & 15,00 \\
\hline \multirow[t]{2}{*}{7} & 120 & 104 & 105 & 105 & 104,7 & 12,78 \\
\hline & & & & \multicolumn{2}{|c|}{ Average } & 23,36 \\
\hline
\end{tabular}

Table 2 : Testing Data Soft Steel Plate $1 \mathrm{~mm}$ Thick

\begin{tabular}{ccccccc}
\hline \multirow{2}{*}{ No } & Angel $\boldsymbol{\alpha}$ & $\mathbf{1}$ & $\mathbf{2}$ & $\mathbf{3}$ & Average & $\begin{array}{c}\text { Ratio (\%) } \\
\text { Spring Back }\end{array}$ \\
\cline { 2 - 6 } 1 & 20 & 16 & 18 & 18 & 17,33 & 13,33 \\
2 & 40 & 35 & 34 & 34 & 34,33 & 14,17 \\
3 & 60 & 54 & 54 & 55 & 54,33 & 9,44 \\
4 & 80 & 74 & 74 & 73 & 73,67 & 7,92 \\
5 & 90 & 83 & 85 & 82 & 83,33 & 7,41 \\
6 & 100 & 94 & 96 & 95 & 95 & 5 \\
7 & 120 & 112 & 116 & 115 & 114,3 & 4,72 \\
\hline
\end{tabular}

Table 3 : Testing Data of $2 \mathrm{~mm}$ Thickness Malleable Steel Plate

\begin{tabular}{|c|c|c|c|c|c|c|}
\hline \multirow{2}{*}{ No } & \multirow{2}{*}{ Angel $\alpha$} & \multicolumn{4}{|c|}{ Thick 2 mm } & \multirow{2}{*}{$\begin{array}{c}\text { Ratio (\%) } \\
\text { Spring Back }\end{array}$} \\
\hline & & 1 & 2 & 3 & Average & \\
\hline 1 & 20 & 20 & 19 & 19 & 19,33 & 3,33 \\
\hline 2 & 40 & 39 & 38 & 38 & 38,33 & 4,17 \\
\hline 3 & 60 & 58 & 56 & 55 & 56,33 & 6,11 \\
\hline 4 & 80 & 78 & 79 & 78 & 78,33 & 2,08 \\
\hline 5 & 90 & 86 & 88 & 87 & 87 & 3,33 \\
\hline 6 & 100 & 99 & 97 & 97 & 97,67 & 2,33 \\
\hline \multirow[t]{2}{*}{7} & 120 & 118 & 119 & 116 & 117,7 & 1,94 \\
\hline & & & & \multicolumn{2}{|c|}{ Average } & $\mathbf{3 , 3 3}$ \\
\hline
\end{tabular}


Table 4 : Testing Data of $4 \mathrm{~mm}$ Thickness Malleable Steel Plate

\begin{tabular}{|c|c|c|c|c|c|c|}
\hline \multirow{2}{*}{ No } & \multirow{2}{*}{ Angel $\alpha$} & \multicolumn{4}{|c|}{ Thick 4 mm } & \multirow{2}{*}{$\begin{array}{c}\text { Ratio (\%) } \\
\text { Spring Back }\end{array}$} \\
\hline & & 1 & 2 & 3 & Average & \\
\hline 1 & 20 & 20 & 19 & 20 & 19,67 & 1,67 \\
\hline 2 & 40 & 40 & 39 & 39 & 39,33 & 1,67 \\
\hline 3 & 60 & 59 & 59 & 58 & 58,67 & 2,22 \\
\hline 4 & 80 & 79 & 80 & 80 & 79,67 & 0,42 \\
\hline 5 & 90 & 88 & 90 & 89 & 89 & 1,11 \\
\hline 6 & 100 & 100 & 98 & 98 & 98,67 & 1,33 \\
\hline \multirow[t]{2}{*}{7} & 120 & 119 & 120 & 118 & 119 & 0,83 \\
\hline & & & \multicolumn{3}{|c|}{ Average } & 1,32 \\
\hline
\end{tabular}

\section{Graph of Bending Angle and Reverse Angle Relation}

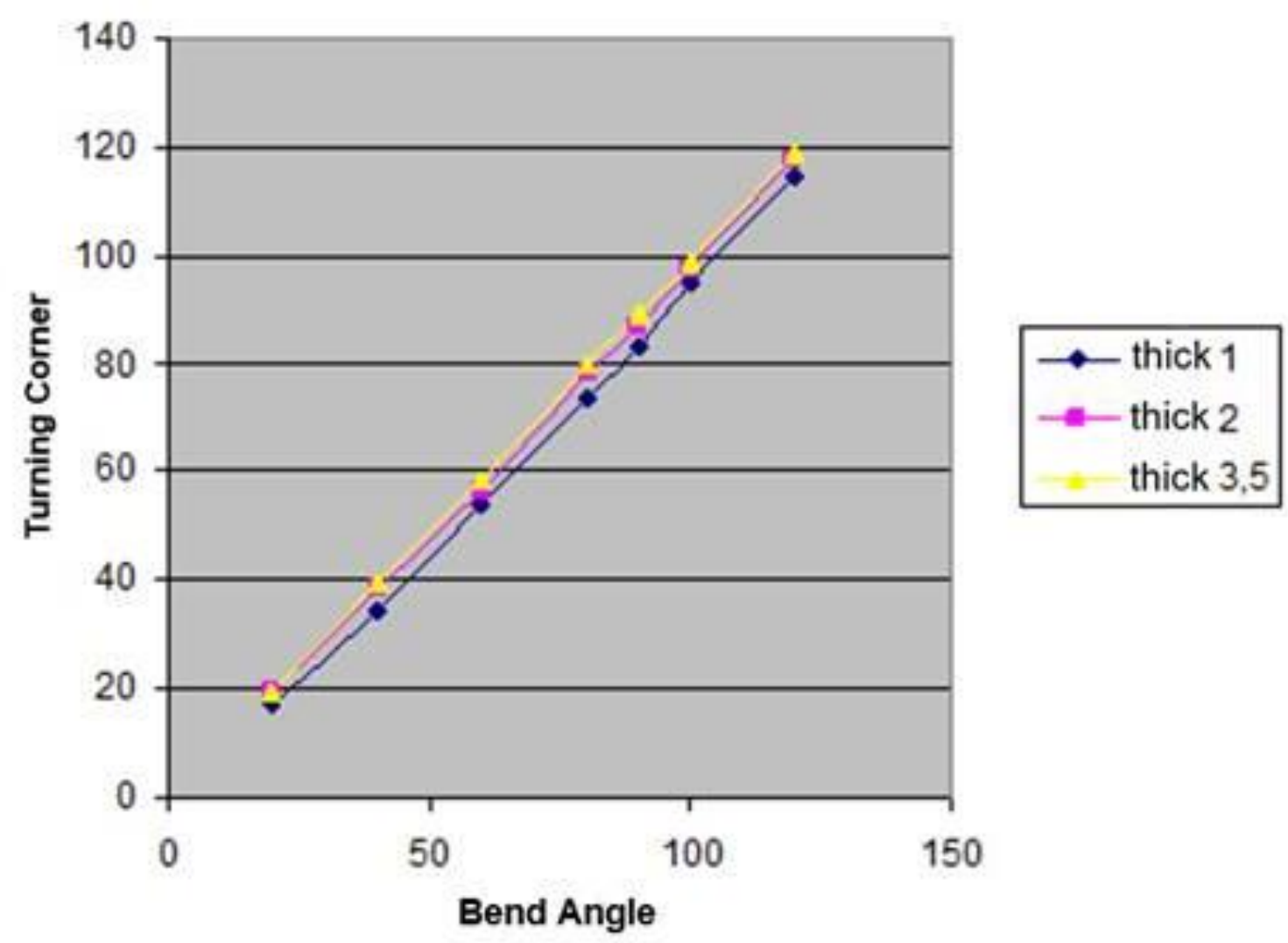

Figure 5: Graph of Bending Anglel and Reverse Angle Relation 
Table 5 : Material Thickness Data and Spring Back Ratio

\begin{tabular}{ccc}
\hline No & Tebal & Ratio SB \\
\hline 1 & 1 & 8.86 \\
2 & 2 & 3.33 \\
3 & 4 & 1.32 \\
\hline
\end{tabular}

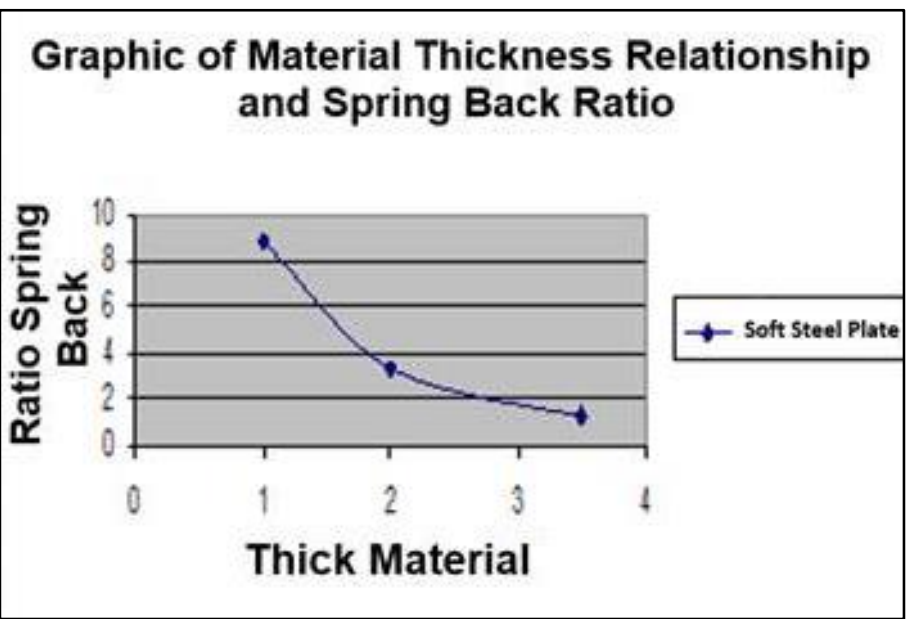

Figure 6 : Graphic of Material Thickness Relationship and Spring Back Ratio

Results of the tests carried out show that the spring back that occurs in the material due to this bending process always occurs and cannot be avoided. This is probably due to the resilience or elastic properties of a material. Amount of the spring back ratio is calculated based on the ratio of the bending angle and the turning angle. In testing the zinc plate with a thickness of $0.3 \mathrm{~mm}$, the spring back ratio resulted in $23.36 \%$. This means that the zinc plate that is bent has a great tendency to reverse it. For example, for a bending angle of $90^{\circ}$ the plate position is reversed to $75^{\circ}$. When compared with the soft steel plate material, the bending angle of $90^{\circ}$, the position of the plate is reversed to be $83^{\circ}-89^{\circ}$. Test table shows the average spring back ratio for soft steel plate between $1.32 \%$ to $8.86 \%$. If it is observed in the test table for each change in formation angle, the return angle is relatively the same for each of the same plate thickness. From the tests carried out on a plate thickness of $1 \mathrm{~mm}$ at a bending angle of $20^{\circ}$, the turning angle is $17.33^{\circ}$ and the bending angle is $120^{\circ}$, the turning angle is $114.33^{\circ}$. Spring back ratio that occurred in the test with a plate thickness of $1 \mathrm{~mm}$ experienced a change of $13.33 \%$ and the smallest was $4.72 \%$. In the graph of the relationship between plate thickness and spring-back ratio, it also shows that the thickness of the bent plate produces a small spring back ratio.

\section{CONCLUSION}

The results of testing and discussion conclude that each steel has a spring back ratio value, which depends on the value of the elasticity of the steel it has. value of the spring back ratio is influenced by several parameters, namely thickness, material type, bending angle being worked. parameters that cause the change in the spring back ratio must be considered during the plate forming process. For example, in the process of bending steel with a bending angle of $90^{\circ}$, when bending it, the bending angle of the shoe must be greater than $90^{\circ}$. number of deviants studied generally ranged from $1 \%$ to $10 \%$. This range of deviations must be considered if a relatively large number of forming processes are to be carried out. Because if there is an error in the bending process, it will take additional time for the repair process. Especially if the process of bending it uses dies and punches, because the dies and puchs must be made first. The advantages of using dies and puchs will produce the same product or have good inter-change ability. It is recommended that observers of the process of forming thin plates should always consider the size of the spring back ratio for the process of forming plates into certain shapes. amount of this deviation must always be seen from the condition of the thickness of the material used, the type of material and the amount of bending angle that is to be achieved. If 
this is allowed to continue, then during the assembly process these components will experience coercion in the connection. This situation will cause the steel to experience side stress due to the process of fitting in the field.

\section{REFERENCES}

[1] Afri Sujarmanto. Metal forming process. 2007

[2] Amstead, B.H. Manufacturing Processes. New York: John Wiley and Son. 1979.

[3] Avitzur, Betzalel. Metal Forming: Processes and Analysis. New York: Mc Graw Hill. 1977.

[4] Kalpakjian S. Manufacturing Engineering \& Technology Access Code. Prentice Hall. 2009.

[5] Corkson, William, Sheet Metal Work. London: Oxford Technical Press. 1975.

[6] Kalpakjian, Scrope. Manufacturing Processes for Engineering Materials. Canada: Addison Wesley Publishing Company. Korb, Lawrence, et.al. Metals Handbook. Ohio: ASM International. 1984.

[7] Lyman. T, Sheet Metal Hand Book. New York: ILO. 1968.

[8] Meyer, Leo. A. Sheet Metal Shop Practice. Chicago: Ais Publication. 1975.

[9] Mills, Kathleen, et.al. Metals Handbook. United States of Amerika: ASM International. 1995.

[10] Yuntao Song*, Damao Yao, Songtao Wu, Peide Weng. Institute of Plasma Physics, Chinese Academy of Sciences, (ASIPP) P.O. Box 1126, Hefei, Anhui, 23003. 2007 